\title{
HYBRID ORIENTATION OF ORGANIZATIONAL IDENTITY AND ITS RELATION TO PARTICULAR ORGANIZATIONAL COMPONENTS ${ }^{1}$
}

\author{
Miloslava Hiršová, Lenka Komárková, Petr Pirožek ${ }^{*}$
}

\begin{abstract}
In coping with organizational changes in the current turbulent environment, focus is primarily placed on structural, "hard" factors, while socio-dynamic processes, which are related to them, are somewhat overlooked. Organizational identity represents the output of processes of staff identification with the organization. We focus on four types of organizational identity orientation: team, working groups, individual and especially hybrid. The goal of this paper is to detect whether the presumed heritage of identity of the socialist organization - in the form of hybrid orientation - persists in the period of transition, and how this orientation relates to selected characteristics of organizations today. Our study is based on the questionnaire survey among 219 organizations and shows that hybrid orientation of identity is still present either directly or can be hidden behind the form of working groups. Results of multiple ordinal regression analysis demonstrate that hybrid orientation of identity prevails in organizations with weak organizational culture that can provide an environment for the manipulative enforcement of individual interests. Our study is an attempt to understand how differences in organizational design may be associated with the arrangement of social relations and be reflected in the form of organizational identity orientations. A better understanding of these processes can improve managerial decision-making in situations when the change of external conditions raises the change of internal settings.
\end{abstract}

Keywords: organizational identity, organizational culture, identity orientation, hybrid orientation of identity, contingency theory, social identity theory, social cognitive theory

JEL Classification: D23, L20

\section{Introduction}

The political and economic changes that occurred in 1989 in Central and Eastern Europe significantly affected nearly every aspect of the lives of local people. The adaptation strategies which had functioned until then lost their effectiveness, numerous social relations were broken and there were frequent and sudden changes in the structure and content of the social roles of individuals. It can be assumed that these phenomena were associated with changes in the social identity of individuals and were reflected in the identities of organizations operating in such a turbulent environment.

These specific political, economic and social conditions certainly cannot be the only variables that affect the behaviour and experience of people in the work environment.

1 This paper was supported by the Czech Science Foundation (GAČR) under the grant number 18-01159S.

* University of Economics, Prague, Faculty of Management (miloslava.hirsova@vse.cz). 
In addition to individual personality characteristics, other factors and their interactions also play a role here (Donaldson and Preston, 1995). The transition from a planned economy to a market environment offered many opportunities for researchers to verify existing knowledge achieved by organizational theory as well as an opportunity for its further development (Whitley and Czaban, 1998; Soulsby and Clark, 2007; Clark and Soulsby, 2007). Although there are valuable studies dealing with sensemaking and sense-giving processes associated with the change of organizational identity (hereinafter OI) in the context of the former socialist organizations transformation (Clark and Soulsby, 2012; Soulsby and Clark, 2013), their qualitative approach does not allow looking for significant relations between these processes and other factors playing a role in the organizational settings by applying statistical methods of analysis.

We would like to build on these studies and contribute to the development of knowledge in this field by defining a conceptual framework that would enable us to link theoretical knowledge regarding organizational settings and people who work in them. Our approach primarily uses contingency theory (Lawrence and Lorsch, 1967; Trist, 1981; Donaldson, 2001), the theory of self-categorization (Turner, 1982), the theory of social identity (Tajfel, 1982; Tajfel and Turner, 1979, 1986) and social cognitive theory (Bandura, 1986, 1988). We believe that despite the revolutionary social changes, running profit organizations is in general directed by the laws derived from the above-mentioned theories and it tries (whether intentionally planned or intuitively) to achieve the optimal fit of contingencies. Unlike studies which deal mainly with issues of optimal organizational design, we want to draw the attention of leaders to the role of the human factor.

\section{Theoretical Background}

\subsection{Organizational Identity}

We assume that the main goals of organizations working in the market environment are performance, productivity and efficiency; usually set within the context of limited material and financial resources. Therefore, emphasis has been placed on working with human resources since the end of the last century, with the requirements for the soft skills of managers or leaders having grown up (Schweiker, 1997; Abdullah, Uli and Tarí, 2008; Cooper and Thatcher, 2010; Van Velsor and Wright, 2013). However, if we were to define the concept of soft skills and look for relationships between them and other components of organizational behaviour and organizational design, we have to face the serious methodological problem of the dimensionality of variables as well as difficulties in controlling intervening variables.

This led us to the decision to apply a "top-down" approach in which we try to find a general umbrella term that could aggregate the function of soft factors as well as the competence of leaders to work with them and could represent them as a whole when identifying their relationship with other contingencies. We assume that OI could serve as this umbrella concept as it is derived from the processes of identifying individuals with organizations and thus reflects their cognitive processing of environmental conditions, including changes that occur in it (Jones and Volpe, 2011; He and Brown, 2013). By serving as a key instrument of sense-giving and sense-making, it gives them important clues to self-regulation in this environment. 
In accord with scholars, we perceive OI as analogy of an individual's identity. The content of OI are central, enduring and distinguishing attributes associated with key values shared in the organization and functioning as categorical imperatives in decisions made in key situations (Albert and Whetten, 1985; Whetten and Godrey, 1998; Whetten, 2006). Like Gioia, Thomas, Clark and Chittipeddi (1994), we believe that these categorical imperatives may not be explicitly stated, because they can function as group awareness of the organizations' members. It contains the shared beliefs in the central, enduring, and distinguishing (and similar) features. It is construed through discourse, resulting from social interactions between members of the organization, and between members of the organization and the external environment. It enables an organization to define itself towards others and still remain itself, which is the essential assumption of sharing its own uniqueness with others and, thus, cooperating with them (Harquail and King, 2003; Haslam and Ellemers, 2005).

Our concept of OI as an indicator of the quality of managerial soft skills is based on the belief that in addition to the individual characteristics, this process of identification is affected by methods motivating the quality of communication in the organization, leadership styles, and other soft factors. These are tied to the ability of a manager to link these elements to the broader context which organizations operate in and with the choice of an appropriate strategy, which takes into account not only the motivation of individuals, but also the motivation of the group as a whole (Lewis, 2011). The degree of job satisfaction contributes to the fact that workers more deeply identify with the values and norms of the organization and are more willing to share their culture and identity. Thus, this process is not only associated with the formation of the individual self, or "who I am", but also of with the group awareness, "who we are".

Given that motivational processes form the basis of our concept of OI as an umbrella construct, our methodological approach applies the conceptual framework of OI orientation introduced by Brickson (2000, 2005, 2007), further elaborated by the example from Cooper and Thatcher (2010). We proceeded mainly from Brickson's conception of motivation base of an identity, where she distinguishes three main sources of motivation: selfinterests, interpersonal benefits and collective welfare. This conceptual framework, based on Brewer's and Gardner's (1996) classification of processes of identification, describes the identification processes as sharing of cognitive patterns and values that relate to the experience of the character of social interactions and the social relations resulting from them. These relations can take on the character of central, permanent and distinguishing features of the organization.

Starting from Whetten's (2006) concept that differentiates the functional standard of organization to which the distinguishing features are linked, and the structural standard related to the central and endurable features, we can conclude that Brickson's $(2005,2007)$ concept rather refers to the functional standard and thus primarily captures the distinguishing features of OI. As such, it will be strongly based on the organizational climate and tied to the quality of relationships in the organization. But with regards to the needs of decision-making on organizational design optimizing and on optimal arrangement of contingencies that play a role in it, it would be more suitable to focus on the structural standard of the organization and think about the central features of OI that are shared by members of the organization and viewed as an important part of the picture of "who we are". 
Although contingency theory is subject to efforts for its enhancement by newer approaches (Brown, 2008; Qiu, Donaldson and Luo, 2012; Meyer, Tsui and Hinings, 1993), we agree with Van de Ven, Ganco and Hinings (2013), by its essence it still remains an important source of knowledge by the means of which a way to maximize organizational performance by minimizing discrepancies and tensions between the diverse requirements of the environment and the internal structure of the organization can be sought. Achieving the goals of an organization is connected with the necessity of division of labour and thus the distribution of social positions in the organization. An individual that enters into an organization usually has an idea of the positions that are available as well as on the content of the roles that are attached to them. Within the processes of cognitive analysis, by which he/she creates a picture of the environment into which he/she enters, he/she is also considering the opportunities for his/her social integration, and compares its requirements with his/her conditions and on the basis of this he/she regulates his/her behaviour (Bandura, 1988). One of the most important social motives that function here is the need for self-enhancement (Tajfel and Turner, 1979).

Tajfel's and Turner's (1986) work leads to the theory of social identity and theory of self-categorization, allowing us to understand better what can happen in situations of organizational design changes, associated with changes in the structure and content of social positions in organization. From this perspective, it is particularly important, whether and how the permeability of social categories is changing; namely, whether the conditions allow mobility between social units, which serves for self-enhancement, or if it does not (Haslam, Powel and Turner, 2000; Elstak, Bhatt, Van Riel, Pratt and Berens, 2015). The outcomes of the assessment of these conditions lead to different strategies associated with different motivation: in the case of possible mobility, the individualistic motives prevail, while there, where social mobility is not possible, this part of the individual's motivation is oriented socially and takes a form of strategies of social creativity or social competition (Tajfel and Turner, 1979, 1986).

Given that social arrangement of organization, from which these motivational processes arise, is an integral part of how members perceive their organization, what they share in it ("it goes like this at us") and what serves as an important factor for decision-making in situations "at a crossroads", we are convinced that the beliefs about the legitimacy of social settings of an organization (Haslam, 2001; Haveman and David, 2008; Bridwell-Mitchell and Mezias, 2012) and the related motivational processes can be considered as one of the central features of OI.

\subsection{Organizational Identity Orientation}

The research conducted for selected features of OI comes from their connection to the culture and the environment in which the organization operates. It assumes that the behaviour patterns of members of an organization are motivationally based on shared forms of socially oriented beliefs. Motivational sources were simplified for our purposes to self-interest and collective welfare on the basis of Tajfel's and Turner's concept of self-categorization processes. This also corresponds to the dimension of Management and Membership described by Alvesson and Empson (2008) as one of the four dimensions by the means of which OI can be construed.

Another recognized element is the management style embedded in the organizational culture. External regulation of the behaviour of organizations' members can take the form 
of orders, within the scope of a securely set hierarchy of the management. Or it may allow for autonomy and room for self-regulation to a large extent. Thus, we obtain the model of the orientation type of OI by linking shared cultural norms to forms of work behaviour regulation, and to a kind of interests related to the social motivation beliefs (see Table 1).

Table 1 | Types of OI orientation

\begin{tabular}{|l|l|c|c|}
\hline \multicolumn{2}{|c|}{ Organizational Identity Orientation } & \multicolumn{2}{c|}{ Interest in the organization's environment } \\
\cline { 3 - 4 } & personal & team \\
\hline \multirow{2}{*}{ Group behaviour } & autonomous & individual & working group \\
\cline { 2 - 4 } & forced orders & hybrid & \\
\hline
\end{tabular}

Source: Authors' own concept based on adaptation of Brickson (2005) and Pirožek (2005).

The type of team orientation is based on the concept of "interdependent people" (Plamínek, 2000), where team members subordinate their personal interests to the needs of the whole, i.e. the interests of the organization. Simultaneously, these interests can be realized through free will because employees identify with the culture of the organization, share its goals and are capable of adaptive self-regulation in achieving them.

Individual orientation of OI represents the sharing of tolerance for an individual's behaviour with a clear demonstration of personal interests, if those are not in direct conflict with organizational goals. An individual or team orientation has also retained a high degree of autonomy in decision-making and in implementation of working tasks.

The orientation of a type of working group is the opposite of the individual orientation. It assumes that the organization is able to unite the satisfaction of staff's needs with the satisfaction of its own needs, and so the work behaviour respects the interests of the whole. However, the identification of employees with the organization can be weak and rather utilitarian, or the character of work does not allow a higher degree of autonomy, so that work behaviour requires regulation by orders.

The last type of socially oriented beliefs, hybrid orientation (Whetten, 2006; Brickson, 2005), rather accurately reflects a management system in which most workers are not able to make decisions in situations of fundamental performances related to work. In that way, the most capable and talented individuals should decide for them, while the responsibility is carried by the entire collective (Boaz, 1997). As a result of this, there are social groupings where people work under orders and pressure that are based on the personal interests of an individual (or individuals) with a formal source of power. The basic tool for promoting the individual interests is the manipulation of the collective's members and goals. The results of the collective are then presented as an interest of the organization. In the proposed model, hybrid orientation is thus characterized by the dominance of individual interests as to be pursued through the whole. The behaviour of members is formally managed through orders and manipulation. In our opinion, this often happen when the changed conditions do not enable social mobility anymore and there are strong individuals in the group who were used to assert self-enhancement by moving to reference group and now feel limited by new conditions. 


\subsection{Components of Organization}

According to Morton (1991) and Pirožek (2005), basic components of an organization's management are environment, structure and culture components (Table 2). For the purpose of this study, one elemental component from each organization component were considered, see Table 2, marked in bold.

Table 2 | Relations of the Ol orientation to the components of organization

\begin{tabular}{|c|c|}
\hline Component of Organization & Elemental Component \\
\hline \multirow{4}{*}{ Structure } & Structural Dimensions \\
\cline { 2 - 2 } & Competence in the Structural Hierarchy \\
\cline { 2 - 2 } & Structural Creation \\
\hline \multirow{2}{*}{ Environment } & Environmental Dynamics \\
\cline { 2 - 2 } & Organizational Image \\
\cline { 2 - 2 } & Profit or Non-profit Orientation \\
\hline \multirow{2}{*}{ Culture } & Culture Strength \\
\cline { 2 - 2 } & Cultural Elements \\
\cline { 2 - 2 } & Cultural Focus \\
\hline
\end{tabular}

Source: Authors' own processing based on Morton (1991) and Pirožek (2005).

The organization's environment in general is characterized by uncertainties of external conditions (Donnelly, Gibson and Ivancevich, 1997) and it may take the form of two bipolar conditions. It is a dynamic environment characterized by considerable variability, when the predictability of the future conditions is very difficult, almost impossible. It is a static environment, characterized by stability, which allows good predictability of future conditions (Brown and Starkey, 2000).

Organizational structure defines the concept of work organization in the perspective of dimensions, competencies and access to organizational planning (Donnelly et al., 1997). The concept of competency resp. competence can be understood from two basic perspectives - behavioural and classical management. The behavioural approach combines competencies with the personal skills of a person, or with the required characteristics of a job. It is related to the nature of work performance. The classical management approach understands the concept of competence as an authorization to rule, which is associated with a specific job position in the organizational hierarchy.

Although most authors dealing with the organizational culture concur with the idea that the nature of organizational culture is sharing, opinions differ on the definition of what is shared. As to the content of organizational culture, we start from Schein's (2004) approach. We believe that the degree of sharing principles important for everyday work routine would be reflected also in the degree of sharing principles on which the concept "who we are" is based. When examining the relationship between the types of OI 
orientation and organizational culture, we therefore focused on monitoring the strength of organizational culture as a possible indicator of the OI sharing.

\section{Study Aim and Working Hypotheses}

Our goal is to detect whether the presumed heritage of identity of the socialist organization - in the form of hybrid orientation - persists in the period of transition, and how this orientation relates to selected characteristics of organizations today. Yet, even though the transition to a market economy has already been gone through many years ago, we can often hear statements of Czech employees at companies who say that in this respect nothing has changed. The main reason for this choice is the fact that among the four selected types of socially oriented beliefs the hybrid orientation may be the biggest source of serious problems in the organization as it carries a strong potential for intractable conflicts (Fiol et al., 2009). The study is therefore based on the following three working hypotheses:

- H1. Hybrid orientation of identity is significantly represented in organizations with traditional conceptions of competences.

- H2. Hybrid orientation of identity is significantly represented in organizations operating in a stable environment.

- H3. Hybrid orientation of identity prevails in organizations with weak organizational culture.

We have no chance to compare OI of contemporary organizations operating in the Czech Republic with the identity of those that worked here before the transition to the market environment. Nevertheless, we believe the key factor which in this situation has worked in the formation of new identities is primarily the perceived change in the social environment and internal motivational conditions of the organization's members related to this change. We are aware that our approach is a simplification of a very complex issue, but we want to make sure whether elements of OI actually play a role in organizational design, so that the findings could enable more detailed research in this field. That is why we investigate the relationship of other three considered OI orientations to select organizations' elemental components which are also involved in organizational design shaping. The next goal is the comparison of selected components of OI between domestic and foreign organizations, and across economic sectors. Our experience from practice shows that hybrid orientation of OI can be a latent phenomenon mainly in working groups. According to Brickson $(2005,2007)$, working groups as a form of organizational design based on the division of labour are common in the manufacturing industry. Thus, other two working hypotheses addressed to hybrid OI orientation are formulated:

- H4. Hybrid orientation of identity prevails in domestic organizations.

- H5. Hybrid orientation of identity prevails in the secondary economic sector.

\section{Data and Methods}


The data relating to the identification of different types of an OI orientation, and of the observed components of organization, were obtained through semi-structured interviews. The preparation of research was carried out in several phases. In 2009-2010, the content of the questionnaire was formulated, based on the theoretical background of the research area. The preliminary surveys took place in selected organizations in the following year and they were aimed at verifying comprehensibility for respondents, as well as the correct conduct of interviewers. Then there was a pilot survey on a sample of 77 organizations, the evaluation of which, including the incorporation of the interviewer's experience, was the basis for a subsequent in-depth investigation. Results from a pilot study focusing only on the culture component were presented by Vinsova et al. (2012).

The main phase of data collecting was in 2011-2013. Our research sample was obtained on the basis of technical feasibility and availability. Organizations were first contacted via their employees - students attending the blended learning program at the Faculty of Management, University of Economics, Prague. Those organizations that were willing to undergo a structured interview were included in the sample. Our effort was to get a sample of 200-300 for-profit organizations, therefore the data collection took about three years. Finally, it included a total of 220 companies operating in the Czech Republic. For the purpose of our study, data were acquired from the companies in two ways. Representatives of senior management of selected companies were contacted through a semi-structured questionnaire which also allowed the respondent's own answer. The interviewers were trained for this purpose. In order to achieve higher accuracy of answers, the interviewers put down their own notes in addition to recording answers, and experts then evaluated these notes and answers together. One questionnaire was excluded due to inconsistent answers. Therefore, our research sample consists of 219 organizations.

The content of the questionnaire and its structure were based on the above basic components (structure, environment, culture) of the organization, going on to examine OI in which the organization operates. Each component of the organization was represented by one ordinal item. A five-point rating scale (structure: 1 - traditional approach / 5 - behavioural concept; environment: 1 - stable / 5 - dynamic; culture: 1 - weak / 5 -strong) was prepared in advance to assess most variables that characterize the individual organizational components so that the following quantitative analysis might be possible. Similarly, each of four considered types of OI orientation was also investigated using a five-point ordinal scale ( 1 - weak / 5 - strong). Regarding the methodological point of view, we proceeded similarly as Brickson (2005), who investigated the dependence of quantitative data converted from qualitative data by means of coding. The questions were based on Brickson's (2007) description of external and internal social value potentiality concerning particular types of OI orientation.

The research sample is introduced using Table 3 a 4 . It covered both $129(58.9 \%)$ domestic and $90(41.1 \%)$ foreign for-profit organizations. The range of staff was from 2 to 246,000. The sample thus contained small, medium and large organizations (Table 3). The majority $(98.2 \%)$ of organizations operate outside of primary economic sector. In particular, 120 (72 with domestic, 48 with foreign owner) organizations provide services (Table 4).

The acquired data was summarized with the help of descriptive statistics tools. With respect to the ordinal nature of the OI orientation variable, the dependence of the type 
of OI orientation on the selected elements of the structural component, environment and culture, and also on ownership and economic sector, was assessed by a multiple ordinal regression which belongs to the class of generalized linear models. For the analysis, we used R software version 3.5.1 (R Core Team, 2018), namely R-package VGAM.

Table 3 | Owner and size of the organization - Absolute (relative) frequency of organizations

\begin{tabular}{|l|r|r|r|}
\hline Type of Organization & \multicolumn{1}{|c|}{ Domestic } & \multicolumn{1}{c|}{ Foreign } & \multicolumn{1}{c|}{ Total } \\
\hline Micro (0-9 employees) & $6(2.7 \%)$ & $0(0.0 \%)$ & $6(2.7 \%)$ \\
\hline Small (10-49 employees) & $43(19.6 \%)$ & $9(4.1 \%)$ & $50(23.7 \%)$ \\
\hline Medium (50-249 employees) & $48(21.9 \%)$ & $25(11.4 \%)$ & $73(33.3 \%)$ \\
\hline Large (250 and more employees) & $32(14.6 \%)$ & $56(25.6 \%)$ & $88(40.2 \%)$ \\
\hline Total & $\mathbf{1 2 9}(\mathbf{5 8 . 9} \%)$ & $\mathbf{9 0 ( 4 9 . 1 \% )}$ & $\mathbf{2 1 9}(\mathbf{1 0 0 . 0 \% )}$ \\
\hline
\end{tabular}

Source: Authors' own research

Table 4 | Owner and economic sector of the organization - Absolute (relative) frequency of organizations

\begin{tabular}{|l|c|c|c|}
\hline Economic Sector & Domestic & Foreign & Total \\
\hline Primary & $4(1.8 \%)$ & $0(0.0 \%)$ & $4(1.8 \%)$ \\
\hline Secondary & $53(24.2 \%)$ & $42(19.2 \%)$ & $95(43.4 \%)$ \\
\hline Tertiary & $72(32.9 \%)$ & $48(21.9 \%)$ & $120(54.8 \%)$ \\
\hline
\end{tabular}

Source: Authors' own research

\section{Results}

Table 5 shows basic descriptive statistics for OI orientation types according to the ownership. The important information is the level of different types of OI: the higher level (sample mean is greater than 3) of representation in both types of ownership is at group interest (working groups, team) and the lower level of representation (sample mean is lower than 3 ) is at personal interest (individual, hybrid). 
Table 5 | Comparison of type of Ol orientation among organizations with a domestic or foreign owner - Sample Means (and standard deviations)

\begin{tabular}{|l|c|c|c|c|}
\hline Ownership & Hybrid & Individual & Working group & Team \\
\hline Domestic & $2.24(1.30)$ & $2.12(1.02)$ & $3.29(1.22)$ & $3.67(1.30)$ \\
\hline Foreign & $2.49(1.20)$ & $2.07(1.03)$ & $3.36(1.24)$ & $3.72(1.20)$ \\
\hline In Total & $2.34(1.26)$ & $2.10(1.02)$ & $3.32(1.23)$ & $3.69(1.26)$ \\
\hline
\end{tabular}

Source: Authors' own research

Table 6 | Comparison of type of Ol orientation among organizations operating in different economic sectors - Sample Means (and standard deviations)

\begin{tabular}{|l|c|c|c|c|}
\hline Economic Sector & Hybrid & Individual & Working group & Team \\
\hline Primary Sector & $1.50(1.00)$ & $1.25(0.50)$ & $4.25(0.50)$ & $4.00(0.82)$ \\
\hline Secondary Sector & $2.47(1.26)$ & $1.88(0.93)$ & $3.58(1.14)$ & $3.45(1.33)$ \\
\hline Tertiary Sector & $2.27(1.26)$ & $2.30(1.05)$ & $3.08(1.33)$ & $3.88(1.19)$ \\
\hline
\end{tabular}

Source: Authors' own research

Similarly, descriptive analysis for OI orientation with respect of economic sector irrespective of ownership was done, see Table 6. Higher values of sample means can be seen as in previous table for working group and team orientations of OI across all the sectors. Notice that presented values for organizations in primary sector have a very low informative value due to only four organizations in this sector.

Table 7 gives main results from ordinal regression analysis with cumulative logits and proportional odds. We used four analogous models for each OI orientation as a response. Given the small number of organizations in the primary sector (Table 4), organizations from this sector were merged with the organizations from the secondary sector for the purpose of modelling.

Table 7 | Ordinal regression analysis results for OI orientation - Estimates for odds ratios (OR) and $p$-values of related tests

\begin{tabular}{|l|c|c|c|c|c|c|c|c|}
\hline & \multicolumn{2}{|c|}{ Hybrid } & \multicolumn{2}{c|}{ Individual } & \multicolumn{2}{c|}{ Working g. } & \multicolumn{2}{c|}{ Team } \\
\hline Predictor & OR & $\mathbf{p}$ & OR & $\mathbf{p}$ & OR & $\mathbf{p}$ & OR & $\mathbf{p}$ \\
\hline Competence & 0.89 & 0.395 & 1.55 & 0.002 & 0.78 & 0.065 & 1.37 & 0.024 \\
\hline Dynamics & 1.10 & 0.398 & 1.02 & 0.851 & 0.90 & 0.346 & 1.15 & 0.244 \\
\hline Culture strength & 0.68 & 0.001 & 0.78 & 0.033 & 0.91 & 0.428 & 2.31 & $<0.001$ \\
\hline Owner (F vs D) & 1.52 & 0.094 & 0.92 & 0.739 & 1.12 & 0.640 & 1.08 & 0.773 \\
\hline Sector (3 vs 1-2) & 0.74 & 0.241 & 2.17 & 0.003 & 0.51 & 0.008 & 1.76 & 0.029 \\
\hline Overall significance & $\mathbf{X}^{2}$ & $\mathbf{p}$ & $\mathbf{X}^{2}$ & $\mathbf{p}$ & $\mathbf{X}^{2}$ & $\mathbf{p}$ & $\mathbf{X}^{2}$ & $\mathbf{p}$ \\
\hline Wald $\mathrm{X}^{2}$ test & 15.38 & 0.009 & 26.30 & $<0.001$ & 16.07 & 0.007 & 54.07 & $<0.001$ \\
\hline
\end{tabular}

Source: Authors' own research 
For hybrid OI orientation, one statistically significant result at the 5\% significance level can be seen, namely for culture strength $(\mathrm{p}=0.001)$. In particular, with increasing culture strength, odds on stronger hybrid orientation of OI decrease (estimate for OR $<1$ ), adjusted for other considered effects (ceteris paribus principle). For individual OI orientation, we get similar result, see $\mathrm{p}=0.033$ for the predictor Culture strength. Moreover, there are two other significant results (Competence: $p=0.002$ and Sector: $\mathrm{p}=0.003$ ). From point estimates for OR, it follows that the closer to behavioural concept of competence in structural hierarchy, the higher odds on higher values of individual orientation of OI (estimate for OR is 1.55). Individual OI Orientation is more probable at tertiary sector than at the two others.

Focusing on the results for working group orientation of OI, we can see that a significant effect of Sector. Working Group OI Orientation is more probable for the primary or secondary sector than for the tertiary one. Further, in the ordinal regression results for team orientation of OI, there are three significant effects: $1 /$ Competence in structural hierarchy (positive effect when changing the competencies concept from traditional to behavioural); 2/ Culture strength (positive effect); 3 / Sector of economic activity (higher odds on team OI orientation for tertiary sector than for other ones).

\section{Discussion}

In the case of the first working hypothesis assuming that hybrid orientation of identity is significantly represented in organizations with traditional conceptions of competences, we managed to give a statistical evidence for their connection with individual or team orientation of OI at the 5\% level. Considering the value of OR estimate, we can state that the closer the competences in the organization are to the behavioural approach, the more frequently we can find the individual behaviour and the team type of the OI orientation. This corresponds with the openness of this managerial style, based on the importance of skills, to self-enhancement and social mobility (Tajfel and Turner, 1979). Our results do not support H1, however, if we conceptualize collectivism as a broader concept of hybrid identity orientation or of working group, we can see one result nearly significant $(\mathrm{p}=0.065)$. If there is a fixed hierarchical structure in an organization, with clearly defined sources of power, it is expected that OI will not be single-layered, but it will copy the distribution of power. Thus, OI cannot be used as a generally applicable guideline to automatic regulation for all the organizations' members. The coordination of activities and the implementation of decisions therefore must be subordinated to management and control of those who have been authorized to use it (Brewer and Gardner, 1996; Corley, 2004).

As to the $\mathrm{H} 2$ (Hybrid orientation of identity is significantly represented in organizations operating in a stable environment), there is no statistically significant effect on the degree of any orientation of OI, given other explanatory variables, that is competence, culture strength, ownership and sector. Therefore, the second hypothesis (H2) was not supported by our study results. We assumed that stable environment with low demands on flexibility had been an important feature of former socialist organizations where hybrid identity used to have been a frequent phenomenon but it seems from our results that this was not the main precondition and that the individual needs for self-enhancement would be stronger regardless of environmental conditions (Tajfel and Turner, 1979, 1986). 
Regarding the culture strength, the relation to the orientation of OI, consistent with the hypothesis H3 (Hybrid orientation of identity prevails in organizations with weak organizational culture), was demonstrated. The weaker the culture is, the higher the level of hybrid as well as individual type of OI orientation. The stronger culture is connected with the higher degree of team orientation of identity. Although there is no statistical evidence for the connection of the orientation of working group type with the limited power of organizational culture, these findings confirm that the OI is embedded in the organizational culture. They indirectly refer to the importance of the identification processes: if employees do not identify with the organization and its goals, they do not share its culture either (He and Brown, 2013; Jones and Volpe, 2011).

The fourth hypothesis (Hybrid orientation of identity prevails in domestic organizations) was not supported by a statistical significant result at the $5 \%$ level, but only at the $10 \%$ level. Further, the fifth hypothesis (Hybrid orientation of identity prevails in the secondary economic sector) was not statistically confirmed. Given that more than $40 \%$ of organizations forming the sample operate in the secondary sector (manufacturing and industry), it is expected that technological conditions here will require arrangements mainly in the form of working groups (Brickson, 2005). This expectation about the sector effect on working groups OI orientation was statistically confirmed (see Table 9). However, taking into account the frequent critical remarks of Czech employees, it is necessary to surmise the possible effects of the phenomenon of labelling (Gioia, Schultz and Corley, 2000).

We do not know whether or not the current organizations acting in the marketplace take over rhetoric typical for this environment, and if they build their identity in new terms, even though the original content has not changed. The source of OI is the shared experience of the organization's members, reflecting the conditions of the external and internal environment as well as their historical experience. In accordance with Corley (2004), we assume that the perception, on which this sharing is based, may also vary depending on the hierarchical structure of the organization. Managers may be more subject to expectations of the external environment and link OI with strategy, while ordinary workers perceive it more as guidelines for solving common business situations (Corley, 2004). Thus, the results presented may already show an adaptation (or at least a rhetorical adaptation) of executives to the new conditions, while the shared cognitive schemes and experiences of workers at lower levels of the job hierarchy may not have changed. This phenomenon is also described by Soulsby and Clark (2013), who pointed out at politics of some managers aimed at preserving their values, interests and priorities as well as their positions by managing the crucial stakeholders in such a way as to produce pronounced agreement with these aims. We have informal reports from workers of the organizations surveyed affirming that such is indeed the case.

We are aware of some limitations of our study. First, the data obtained are influenced by the nature of empirical inquiry and certain subjectivity of the interviewers, and particularly on the side of the respondents. When formulating the conclusions, we have assumed that surveyed representatives of organizations, according to their work activity associated with the internal environment of the organization, are able to reflect adequately the selected features of identity of their organization and of other characteristics that we monitor. Second, the construction of OI by an individual can be altered by various factors whose impact is unclear to the interviewer. The attempt 
to quantify each organization's elemental component only by one ordinal item carries a considerable risk of oversimplification, resulting in inappropriate interpretations. Nevertheless, we tried to at least partially suppress this problem by checking the consistency of the additional open answers and the interviewer's notes by experts. Third, we realize that the scope of organizations included in the sample is considerably limited in terms of their agreeing to participate in research. These can affect the results we have achieved, namely their external validity. Despite these limitations, we believe that we have managed to draw attention to the fact that, when assessing OI orientation, it is necessary to extend the concept of Brickson (2000) to hybrid forms of OI orientation, as they can have a significant impact on organizational processes and outputs.

\section{Conclusions}

Our study represents an attempt to understand what happens at the working environment when the external conditions are changing while undergoing internal changes. Moreover, it attempts to identify factors playing a key role in these situations. What happens in conditions when the original culture has been weakened by new cultural influence and this new culture has not yet been sufficiently accepted (shared) and established? How are the motives of workers and managers and patterns of behaviour that lead to their satisfaction changing?

We assume that all these changes reflect the historical context as well as interactions with both the internal and external environment and are put into practice in the form of soft skills employed by the manager. In order to quantify this broad concept and relate it to other factors, we chose OI (Whetten, 2006) as a construct that, as the output of the identification processes, represents this field of organizational life and reflects the quality of management styles (Whetten and Godrey, 1998).

OI is conceptualized on the basis of social motives as OI orientation (Brickson, 2000, 2002). These motives are related both to personal and group needs, arising from the processes of self-categorization and serve for the purpose of an individual's social identity, especially for satisfying his/her need of self-enhancement (Tajfel and Turner, 1979, 1986). Their satisfaction is first gained by the opportunities for social mobility in organizations. It is also controlled by the preferred norms of behaviour in the group, which allow individuals either greater autonomy or group behaviour is controlled by commands. The central and distinguishing feature of OI is then based on the values and norms associated with the team or group behaviour, or either on individualistic and hybrid (collectivist) behavioural patterns.

Contingency theory and approaches derived from it (Van de Ven, Ganco and Hinings, 2013; Donaldson, 2001) provide many crucial lessons on how to arrange organizational design. In our paper, we want to point out that the organizational design is closely related to the social structure and social motives of members of the organization. From the perspective of managerial decision-making, it is important to capture a hybrid type of identity orientation, which corresponds to the collectivist concept of socialist organizations. They represent behaviour motivated by the satisfaction of the interests of some individuals in an environment, where the behaviour control by the external commands and by manipulation is dominant.

From the postulated hypotheses, we managed to confirm that hybrid orientation of identity prevails in organizations with weak organizational culture. We have failed 
to show the connection between hybrid orientation of identity with organizations with traditional conception of competencies, neither with organizations operating in a stable environment nor with in organizations of domestic ownership. Although we have not find any study confirming or refuting these results, we can anticipate that social processes aimed at satisfaction of individual needs will play more important role here (Tajfel, Turner, 1976, 1979). However, the results show that individual types of orientation of OI may be associated with certain organizational components, namely with behavioural concept of competences, weak organizational culture and tertiary industrial sector.

Though our results do not allow generalization, they indicate the possibility of creating a space for manipulative assertion of individual interest as known from former "collectives" of socialist organizations. But this phenomenon does not seem to be embedded in particular political background (Creed, 1995), we can assume that it is driven by a variety of other variables linked to the environment of the organization, its structure and strategy as well as to leadership styles influencing the character of social relations in organization.

Based on the experience of processing this paper, we postulate that the construct of $\mathrm{OI}$ as the result of the process of identification with organizational culture and sharing central, endurable and distinguishing features has paramount importance for the shift in recognition of an organization as a living organism, with very complex connections and relations that cannot be mechanically simplified as causal relations. We think that narrative approaches allow for a more intuitive understanding of this phenomenon cognizant of the fact that their findings may be further developed and scientifically reviewed. Vice versa, findings obtained by exact methods must be reviewed by qualitative methods so that we can obtain evidence on their indisputable contents. With respect to the research effectiveness, the mere identification of those constructs which bear the biggest amount of relevant information would be an important contribution.

The practical impact of the development of OI from the past to the present in terms of the transformation of enterprises (Soulsby and Clark, 2013) is important not only for a better understanding of the transformation process itself. In spite of limitations mentioned above, our proposed concept of further research may reveal interactions among the processes shaping OI as well as those shaped by it and their impact on the quality of the working environment, generating synergies, leading to better performance, quality, and efficiency of the company.

\section{References}

Abdullah, M. M. B., Uli, J., \& Tarí, J. J. (2008). The Influence of Soft Factors on Quality Improvement and Performance: Perceptions from Managers. TQM Magazine, 20(5), pp. 436-452. https://doi.org/10.1108/17542730810898412

Albert, S., \& Whetten, D. A. (1985). Organizational Identity. In L. L. Cummings and M. M. Staw, eds., Research in Organizational Behaviour (pp. 263-295). Greenwich, CT: JAI.

Alvesson, M., \& Empson, L. (2008). The Construction of Organizational Identity: Comparative Case Studies of Consulting Firms. Scandinavian Journal of Management, 24(1), pp. 16-37. https://doi.org/10.1016/j.scaman.2007.10.001

Bandura, A. (1986). Social Foundations of Thought and Action: A Social Cognitive Theory. Englewood Cliffs, N.J: Prentice-Hall. 
Bandura, A. (1988). Organizational Application of Social Cognitive Theory. Australian Journal of Management, 13(2), pp. 275-302. https://doi.org/10.5465/amr.1989.4279067

Boaz, D. (1997). Libertarianism: A Primer. New York, NY: Free Press.

Brewer, M. B., \& Gardner, W. (1996). Who Is This 'We'? Levels of Collective Identity and SelfRepresentations. Journal of Personality and Social Psychology, 71, pp. 83-93. https://doi.org/10.1037/0022-3514.71.1.83

Brickson, S. L. (2000). The Impact of Identity Orientation on Individual and Organizational Outcomes in Demographically Diverse Settings. Academy of Management Review, 25, pp. 82-101. https://doi.org/10.5465/amr.2000.2791604

Brickson, S. L. (2005). Organizational Identity Orientation: Making the Link between Organizational Identity and Organizations' Relations with Stakeholders. Administrative Science Quarterly, 50, pp. 576-609. https://doi.org/10.2189/asqu.50.4.576

Brickson, S. L. (2007). Organizational Identity Orientation: The Genesis of the Role of the Firm and Distinct Forms of Social Value. Academy of Management Review, 32(3), pp. 864-888. https://doi.org/10.5465/amr.2007.25275679

Bridwell-Mitchell, E. N., \& Mezias, S. J. (2012). The Quest for Cognitive Legitimacy: Organizational Identity Crafting and Internal Stakeholder Support. Journal of Change Management, 12(2), pp. 189-207. https://doi.org/10.1080/14697017.2011.645053

Brown, A. D., \& Starkey, K. (2000). Organizational Identity and Learning: A Psychodynamic Perspective. Academy of Management Review, 25(10), pp. 102-120. https://doi.org/10.5465/amr.2000.2791605

Brown, T. (2008). Design Thinking. Harvard Business Review, 86(5), pp. 85-92. https://doi.org/10.5040/9781474282932.0020

Clark, E., \& Soulsby, A. (2012). Constructing Post-Socialism: Organisational Identity and the Experience of International Joint Ventures. Europe-Asia Studies, 64(2), pp. 257-280. https://doi.org/10.1080/09668136.2011.646496

Clark, E., \& Soulsby, A. (2007). Understanding Top Management and Organizational Change through Demographic and Processual Analysis. Journal of Management Studies, 44(6), pp. 932-954. https://doi.org/10.1111/j.1467-6486.2007.00692.x

Cooper, D., \& Thatcher, S. (2010). Identification in Organizations: The Role of Self-Concept Orientations and Identification Motives. Academy of Management Review, 35(4), pp. 516-538. https://doi.org/10.5465/AMR.2010.53502693

Corley, K. G. (2004). Defined by Our Strategy or Our Culture? Hierarchical Differences in Perceptions of Organizational Identity and Change. Human Relations, 57(9), pp. 1145-1177. https://doi.org/10.1 177/0018726704047141

Creed, G. W. (1995). The Politics of Agriculture: Identity and Social Sentiment in Bulgaria. Slavic Revue, 54(4), pp. 843-868. https://doi.org/10.2307/2501396

Donaldson, L. (2001). The Contingency Theory of Organizations. Thousand Oaks, CA: Sage.

Donaldson, T., \& Preston L. E. (1995). The Stakeholder Theory of the Corporation: Concepts, Evidence, and Implications. The Academy of Management Review, 20(1), pp. 65-91. https://doi.org/10.5465/AMR.1995.9503271992

Donnelly, J. H., Gibson, J. L., \& Ivancevich, J. M. (1997). Management. Praha: Grada.

Elstak, M. N., Bhatt, M., Van Riel, C. B. M., Pratt, M. G., \& Berens, G. A. J. M. (2015). Organizational Identification during a Merger: The Role of Self-Enhancement and Uncertainty Reduction Motives during a Major Organizational Change. Journal of Management Studies, 52(1), pp. 32-62. https://doi.org/10.1111/joms.12105 
Fiol, C. M., Pratt, M. G., \& O'Connor, E. J. (2009). Managing Intractable Identity Conflicts. Academy of Management Review, 34(1), pp. 32-55. https://doi.org/10.5465/amr.2009.35713276

Gioia, D. A., Thomas, J. B., Clark, S. M., \& Chittipeddi, K. (1994). Symbolism and Strategic Change in Academia: The Dynamics of Sensemaking and Influence. Organization Science, 5(3), pp. 363-338. https://doi.org/10.1287/orsc.5.3.363

Gioia, D. A., Shultz, M., \& Corley, K. (2000). Organizational Identity, Image and Adaptive Instability. Academy of Management Review, 25, pp. 64-82. https://doi.org/10.5465/AMR.2000.2791603.

Harquail, C. V., \& King, A. W. (2003). Organizational Identity and Embodied Cognition: A Multilevel Conceptual Framework [paper presented at Academy of Management Antal Meeting, Seattle, WA]. https://doi.org/10.5465/AMBPP.2003.13792529

Haslam, S. A, Powel, C., \& Turner, J. C. (2000). Social Identity, Self-Categorization and Work Motivation: Rethinking the Contribution of the Group to Positive and Sustainable Organizational Outcomes. Applied Psychology: An International Review, 49(3), pp.319-339. https://doi.org/10.1111/1464-0597.00018

Haslam, S. A. (2001). Psychology in Organizations: The Social Identity Approach. London: Sage Publications Ltd.

Haslam, S. A., \& Ellemers, N. (2005). Social Identity in Industrial and Organizational Psychology: Concepts, Controversies and Contributions. In G. P. Hodgkinson, J. K. Ford, eds., International Review of Industrial and Organizational Psychology, Volume 20 (pp. 39-118). Hoboken, NJ: Wiley. https://doi.org/10.1002/0470029307.ch2

Haveman, H., \& David, R. (2008). Ecologists and Institutionalists: Friends or Foes? In R. Greenwood, C. Oliver, K. Sahlin, and R. Suddaby, eds., Handbook of Organizational Institutionalism (pp. 573-590). Oxford, UK: Oxford University Press.

He, H., \& Brown, A. D. (2013). Organizational Identity and Organizational Identification: A Review of the Literature and Suggestions for Future Research. Group \& Organization Management, 38(1), pp.3-35. https://doi.org/10.1177/1059601112473815

Jones, J., \& Volpe, H. E. (2011). Organizational Identification: Extending our Understanding of Social Identities through Social Networks. Journal of Organizational Behavior, 32, pp. 413-434. https://doi.org/10.1002/job.694

Lawrence, P. R., \& Lorsch, J. W. (1967). Differentiation and Integration in Complex Organizations. Administrative Science Quarterly, 12(1), pp. 1-47. https://doi.org/10.2307/2391211

Lewis, T. (2011). Assessing Social Identity and Collective Efficacy as Theories of Group Motivation at Work. The International Journal of Human Resource Management, 22(4), pp. 963-980. https://doi.org/10.1080/09585192.2011.555136

Meyer, A. D., Tsui, A. S., \& Hinings, C. R. (1993). Configurational Approaches to Organizational Analysis. Academy of Management Journal, 36, pp. 1175-1195. https://doi.org/10.2307/256809

Morton, M. S. S. (1991). Corporation of the 1990s - Information Technology and Organizational Transformation. Oxford, UK: Oxford University Press.

Plamínek, J. (2000). Synergický management [Synergic Management]. Praha: Argo.

Pirožek, P. (2005). Management ziskových a neziskových organizací [Management Profit and Non for Profit Organizations, habilitation thesis]. Brno University of Technology. 
Qiu, J., Donaldson, L., \& Luo, B. N. (2012). The Benefits of Persisting with Paradigms in Organizational Research. Academy of Management Perspectives, 26, pp. 93-104. https://doi.org/10.5465/amp.2011.0125

R Core Team (2018). R: A Language and Environment for Statistical Computing. $R$ Foundation for Statistical Computing [online]. Available at: http://www.R-project.org [Accessed 17 Jan. 2019]

Schein, E. H. (2004). Organizational Culture and Leadership (3rd ed.). San Francisco: Jossey-Bass.

Schweiker, U. (1997). Beyond Leadership: Shifting Perspectives in Management Practice. European Journal of Work, 6(4), pp. 431-451. https://doi.org/10.1080/135943297399024

Soulsby, A., \& Clark, E. (2007). Organization Theory and the Post-Socialist Transformation: Contributions to Organizational Knowledge. Human Relations, 60(10), pp. 1419-1442. https://doi.org/10.1177/0018726707083470

Soulsby, A., \& Clark, E. (2013). Organizational Restructuring and Change in Transition Societies: Dominant Coalitions and the Dynamics of Managerial Power and Politics. Competition and Change, 17(2), pp. 176-196. https://doi.org/10.1179/1024529413Z.00000000032

Tajfel, H. (1982). Social Identity and Intergroup Relations. Cambridge, UK: Cambridge University Press.

Tajfel, H., \& Turner, J. C. (1979). An Integrative Theory of Intergroup Conflict. In W. G. Austin, and S. Worchel, eds., The Social Psychology of Intergroup Relations (pp. 33-47). Monterey, CA: Brooks/Cole.

Tajfel, H., \& Turner, J. C. (1986). The Social Identity Theory of Intergroup Behaviour. In W. G. Austin, and S. Worchel, eds., The Social Psychology of Intergroup Relations (pp. 7-24). Chicago: Nelson-Hall.

Trist, E. L. (1981). The Sociotechnical Perspective. In A. H. Van de Ven, and W. F. Joyce, eds., Perspectives on Organizational Behaviour. New York, NY: John Wiley \& Sons.

Turner, J. C. (1982). Towards a Cognitive Redefinition of the Social Group. In H. Tajfel, ed., Social Identity and Intergroup Relations (pp. 15-40). Cambridge, UK: Cambridge University Press.

Van De Ven, A. H., Ganco, M., \& Hinings, C. R. (2013). Returning to the Frontier of Contingency Theory of Organizational and Institutional Designs. The Academy of Management Annals, 7(1), pp. 393-440. https://doi.org/10.1080/19416520.2013.774981

Van Velsor, E., \& Wright, J. (2013). What Do Next-Generation Leaders Look Like? Chief Learning Officer, 12(4), pp. 44-46.

Vinsova, T., Pirozek, P., Pudil, P., \& Komarkova, L. (2012). The Strength of Organizational Culture as a Key Organizational Performance Indicator. In Proceedings of the 3rd Review of Management and Economic Engineering (pp. 190-198). Cluj-Napoca: AMIER and Technical University of Cluj-Napoca.

Whetten, D. A. (2006). Albert and Whetten Revisited. Strengthening the Concept of Organizational Identity. Journal of Management Inquiry, 15(3), pp. 219-234. https://doi.org/10.1177/1056492606291200

Whetten, D. A., \& Godrey, P. C. (1998). Identity in Organizations: Building Theory through Conversations. Thousand Oaks, CA: Sage.

Whitley, R., \& Czaban L. (1998). Ownership, Control and Authority in Emergent Capitalism: Changing Supervisory Relations in Hungarian Industry. International Journal of Human Resource Management, 9(1), pp. 99-115. https://doi.org/10.1080/095851998341215 